\title{
ACTION POINTS
}

Compiled by Tim Albert

Note: The purpose of this page is to encourage dissemination of the findings in $\mathrm{QSHC}$, particularly to managers. Please feel free to photocopy this page and pass it on.

\section{Q: Can releasing performance data reduce litigation?}

In this case report from Australia the authors describe how data from a trainee anaesthetist's performance monitoring programme turned anger into praise. The anaesthetist inadvertently inserted a pulmonary artery catheter sheath into a patient's right carotid artery, resulting in haematoma, distress and dyspnoea. The patient's family complained that a trainee had been allowed to risk a patient's life, and asked how to start formal proceedings. The trainee, who was taking part in a monitoring programme, agreed for his professional record to be shown to the relatives. It showed that he had a very low complication rate for the procedure. "The family then understood more clearly that the sequence of events represented an unfortunate misadventure that could have happened in the hands of any experienced anaesthetist", write the authors. "They were also so impressed by the quality and clarity of the data... . that they requested information on the person to address compliments about a clinical service".

See page 295

\section{- ACTION POINT}

Releasing performance data may help to satisfy patients and reduce litigation.

"The clear lessons from this case are that healthcare managers, health service administrators, medical indemnity organisations, and hospital boards will benefit from encouraging collection of performance data."

\section{www.qshc.com}

\section{Q: To what extent do health professionals in rural areas follow national guidelines?}

Researchers in Scotland studied whether rural practitioners complied with national guidelines. They asked GPs and midwives to propose treatment for two scenarios involving mild hypertension in pregnancy, and followed this up with some telephone interviews. $80 \%$ of the 117 GPs and $63 \%$ of the 121 midwives "overdiagnosed", leading $59 \%$ of them to recommend referral or admission to specialist hospital care. The further the distance from the hospital, the greater was the chance of these recommendations. "It is not possible to determine from our results whether this is a knowledge or training issue around diagnosis, a guideline implementation problem, disagreement with the guideline about illness severity, or magnified perception of risk in management decision making in a rural setting", write the authors. They add that the telephone interviews suggested that accuracy and confidence were key. They conclude: "We suggest that quality improvements could be sought by exploring locally developed guidelines endorsed by all professions in maternity care teams".

See page 286

\section{- ACTION POINT}

National guidelines may need to be supplemented by locally agreed guidelines.

\section{Q: What do patients think of shared care programmes?}

The investigators looked at 248 cancer patients newly referred to the Department of Oncology at Aarhus University Hospital, Denmark. They set up a randomised controlled trial to see whether "shared care" would improve patients' functioning, symptoms, and quality of life. The programme involved:

- discharge summary letters following predefined guidelines, and including names of the doctors and nurses involved;

- a range of patient information on the disease and its treatment;

- oral information to patients about the information available and the desirability of contacting their GP if they had any problems.

The programme had a significant effect on patients' evaluation of issues of cooperation, gave them a feeling of not being "left in limbo", and improved their attitudes to and contacts with GPs. This was particularly pronounced among men and younger patients (18-49 years of age).

See page 263

\section{- ACTION POINT}

Patients will be more positive if there is good communication between them, their GP, and their oncologist.

\section{Q: Will automation reduce medical errors?}

In this article the author warns us to be careful about pinning all our hopes on automation. He warns that more automation is not necessarily desirable, citing a study from aviation that showed that more sophisticated computer support on flight planning tended to reduce critical appraisal. This is dangerous because unanticipated events are bound to occur in complex critical safety systems such as aviation and medicine. One way ahead could be to adopt a "constraint based approach which provides people with rich feedback about the current state of affairs but does not recommend particular courses of action".

See page 291

\section{- ACTION POINT}

Use computers to support decision making, not to supplant it. 